\title{
Spatial Econometric Analysis of the Hungarian Border Crossings
}

\author{
Zsombor Szabó ${ }^{1, *}$, Tibor Sipos $^{1}$, and Árpád Török ${ }^{1}$ \\ ${ }^{1}$ Budapest University of Technology an Economics, Department of Transport Technology and \\ Economics, H-1111 Budapest, Hungary
}

\begin{abstract}
The analysis on the border crossings, as the objects to decrease the separation effect, is really important for our country, to evaluate the connection of the neighbouring and other nearby countries and international economic centres with Hungary. In our country's life the cross-border partnerships have an important role because of historical and cultural causes. In recent article, our task is to analyse changes of the crossborder traffic, with the help of the spatial econometrics. The goal is, to show the effect of five outstanding areas on the crossing traffic, and to analyse the spatial connection between them.
\end{abstract}

\section{Introduction}

The analysis of the borders is exceptional nowadays. While in the European researches the main goal is to find the nature of the relations, in the rest of the world the focus is on the international cooperation's effect on the economy [1,2]. Recent paper's exceptional goal is to describe the system of the relations between the borders, borderlands and border crossings specific parameters and the crossing traffic flow. Numerous papers show that there is a time-based correlation for the flow through the border gates, but now another approach is analysed [3,4]. Numerous international papers have shown, that in case of rating the border crossings locations, the relations between them, or the connected traffic needs, it is advised to take into consideration the properties of the road network system which provide the border crossings (for example: type of the road, international road systems or special infrastructure elements like bridge or tunnel), and the relations with the neighbouring countries especially for the uncontrolled borders described by the international agreements $[5,6]$. Exceptional problem that in Hungary the mean distance between the border crossings is 25 kilometres, while in Western Europe this number is only 5-6. Because of these facts recent papers main goal is to describe a tool which is available for the analysis of the goodness the recent and the planned border crossings. For the tool, the chosen method is the spatial econometrics, although some other methods are available, [7] because numerous papers shown, that this method can be used for answering some questions made by the transportation processes [8].

* Corresponding author: szabo.zsombor@mail.bme.hu 


\section{The used model}

In our model the border crossings of Hungary are analysed by spatial econometric method. For this, the dependent variable will be the traffic flow on each border crossing in vehicle unit/day/two directions. In the analysed time in Hungary there was 103 border crossings, which locations are shown on the next map. (Fig. 1.)

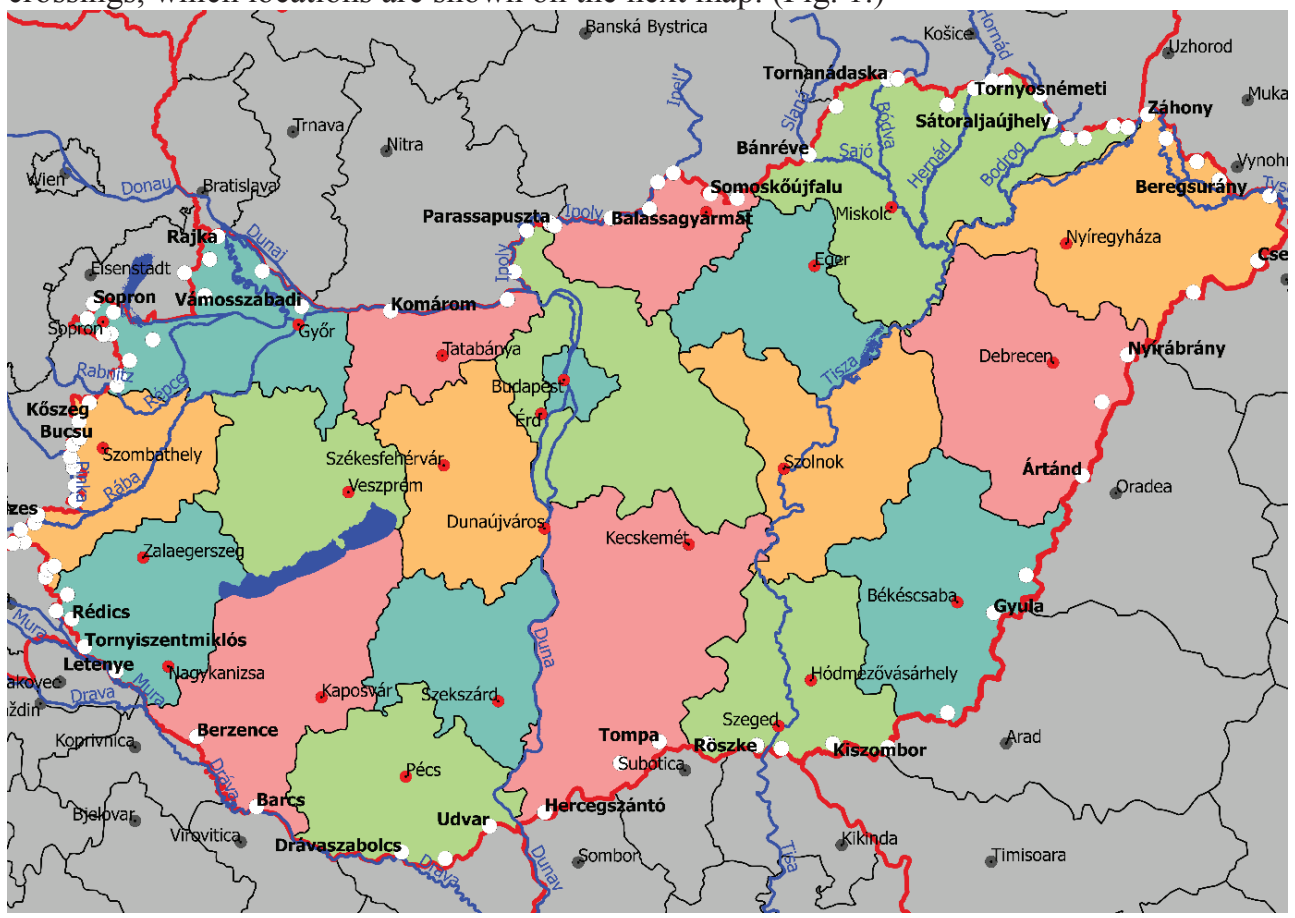

Fig. 1: The map of Hungary's border crossings. Source: authors

The analysis has five outstanding point of view which is need to be considered. These are the next five:

- the effect whether the border gate is on a bridge

- the type of the road

- the effect of the European International E-network

- the country where the border gate is opening

- the effect of the Schengen borders [9]

The analysis of the outstanding effects is in harmony with the past research papers like $[5,6]$.

After than several possible decision variables are eliminated due to multicollinearity issues, the remaining description variables can be organised in numerous groups. The first group is the territories demographic values. In the Hungarian side the populations of the nearest city, the processus (which stands for the NUTS-4 or LAU-1 level) and the county is used. This wide choice of the areas is need to be used because in Hungary 14 out of 19 counties lye near the border [10]. On the other side of the border only the population of the NUTS-3 territories will be used, because the nearest cities p-value is too high to use.

The second group is the rules of the border usage. In this sections five variables are need to be considered. The first is the number of the opening hours in a week, the second is the capacity of the border gate. The third is the total weight capacity for the road, the forth 
is the total weight capacity for the trucks, and the fifth is a dummy variable which is one if the buses are allowed to cross the border at the border gate.

The third group has only one variable which is the effect of the bridge. This is also a dummy variable. It is one, when the border crossing is also a bridge. The fourth group is the different country's dummy variables. In this case there are six variables where Ukraine is the base of the comparison.

The fifth, sixth and seventh groups are considering on the road network. They are dummy variables for the European International E-network, the type of the road in Hungary, and in the neighbouring country also. The last variable, which belongs also to the bridges is the width of the river.

The base model upon the previously shown decision variables, is shown in the next table. The . stands if the $p<0.1$, the $*$ stands if $p<0.05$, the $* *$ stands if $p<0.01$, and $* * *$ stands if $p<0.001$ [11-14]. The model seems to be quite good with $R^{2}=0.7757$, and the p-value of the F-statistics is $1.38^{*} 10^{-14}$.

Table 1. The result of the classic linear regression model. Source: authors, based on [11-14]

\begin{tabular}{|c|c|c|c|c|c|}
\hline \multirow{2}{*}{\multicolumn{2}{|c|}{\begin{tabular}{|l} 
\\
Intercept
\end{tabular}}} & \multirow{2}{*}{$\begin{array}{r}\text { Estimate } \\
2280 \\
\end{array}$} & \multirow{2}{*}{\begin{tabular}{r|} 
Std. Error \\
4271
\end{tabular}} & \multicolumn{2}{|c|}{$\operatorname{Pr}(>|t|)$} \\
\hline & & & & 0.5951 & \\
\hline \multirow{3}{*}{$\begin{array}{l}\text { Hungarian } \\
\text { population }\end{array}$} & County & $3.11 \mathrm{E}-03$ & $1.67 \mathrm{E}-03$ & 0.0669 & \\
\hline & Processus & $-3.53 \mathrm{E}-03$ & $8.28 \mathrm{E}-03$ & 0.6714 & \\
\hline & City & $1.66 \mathrm{E}-01$ & $3.84 \mathrm{E}-02$ & $4.64 \mathrm{E}-05$ & $* * *$ \\
\hline \multicolumn{2}{|c|}{ Neighbouring NUTS-3 population } & $2.13 \mathrm{E}-03$ & $3.99 \mathrm{E}-03$ & 0.5947 & \\
\hline \multirow{5}{*}{ Border crossing } & Opening time & -12.49 & 14.88 & 0.4040 & \\
\hline & Capacity & -0.46 & 0.43 & 0.2840 & \\
\hline & Total weight capacity & 14.47 & 19.81 & 0.4675 & \\
\hline & Truck weight capacity & 1098 & 931.3 & 0.2422 & \\
\hline & Bus banning & -1483 & 1170 & 0.2089 & \\
\hline \multicolumn{2}{|l|}{ Bridge } & -550 & 798 & 0.4928 & \\
\hline \multirow{6}{*}{$\begin{array}{c}\text { Country's } \\
\text { dummies }\end{array}$} & Austria & 5467 & 2004 & 0.0080 & $* *$ \\
\hline & Croatia & -1107 & 1914 & 0.5647 & \\
\hline & Romania & 809.4 & 1863 & 0.6652 & \\
\hline & Serbia & -180.2 & 1899 & 0.9247 & \\
\hline & Slovakia & 1628 & 2294 & 0.4801 & \\
\hline & Slovenia & 4331 & 2199 & 0.0526 & \\
\hline \multirow{3}{*}{$\begin{array}{c}\text { European } \\
\text { international } \\
\text { E-road network }\end{array}$} & A-class reference & 4190 & 1592 & 0.0103 & $*$ \\
\hline & A-class intermediate & -631 & 1348 & 0.6411 & \\
\hline & B-class & 1921 & 1826 & 0.2961 & \\
\hline \multirow{4}{*}{$\begin{array}{l}\text { Hungarian road } \\
\text { dummies }\end{array}$} & Motorway & 8434 & 3458 & 0.0171 & $*$ \\
\hline & Highway & 4580 & 3797 & 0.2315 & \\
\hline & National road & 2641 & 1282 & 0.0429 & $*$ \\
\hline & Other road & 828.8 & 955 & 0.3883 & \\
\hline \multirow{4}{*}{$\begin{array}{l}\text { Neighbouring } \\
\text { road dummies }\end{array}$} & 1st class national road & -2420 & 3123 & 0.4409 & \\
\hline & 2nd class national road & -3717 & 3150 & 0.2418 & \\
\hline & Regional road & -5042 & 3231 & 0.1229 & \\
\hline & Local road & -5601 & 3223 & 0.0864 & \\
\hline \multicolumn{2}{|l|}{ River width } & 4.16 & 3.73 & 0.2680 & \\
\hline
\end{tabular}




\section{Method}

The method is the spatial econometrics based on Luc Anselin [15] and Varga Attila (in Hungarian) [16] works. There are two models which is preferable to use. One is the spatial lag model, where the spatial effects are taken into consideration as a spatial lag, like a time lag in the classic econometrics. The model's mathematical representation is the next (1) [16].

$$
\mathbf{y}_{(N \times 1)}=\rho \mathbf{W}_{(N \times N)} \mathbf{y}_{(N \times 1)}+\mathbf{X}_{(N \times K)} \boldsymbol{\beta}_{(K \times 1)}+\boldsymbol{\varepsilon}_{(N \times 1)}
$$

where:

- y: vector of the dependent variables

- $\rho$ : autoregressive parameter

- W: weight matrix

- $\boldsymbol{\beta}$ : the coefficient vector

- $\mathbf{X}$ : the matrix of the independent variables

- $\boldsymbol{\varepsilon}$ : vector of errors $\left(\mathrm{E}\left(\varepsilon_{i}\right)=0, \mathrm{~V}\left(\varepsilon_{i}\right)=\sigma^{2}\right)$

- N: number of observations

- K: number of independent variables

Among the parameters only the $\rho$ and $\boldsymbol{\beta}$ are unknown. The $\boldsymbol{\beta}$ can be calculated from the $\rho$. Because of the multicollinearity the ordinary least squares method cannot be used. For this, another estimator model should be used, which is the maximum likelihood estimation. Its formula is the next (2) [16].

$$
L_{C}=\sum_{i=1}^{N}\left(1-\rho \omega_{i}\right)-\frac{N}{2} \ln \frac{\left(\mathbf{e}_{0}-\rho \mathbf{e}_{L}\right)^{T}\left(\mathbf{e}_{0}-\rho \mathbf{e}_{L}\right)}{N}
$$

where:

- $\omega_{i}$ : eigen value of the $\mathbf{W}$

- $L_{c}$ : the loglikelihood parameter

- $\mathbf{e}_{0}, \mathbf{e}_{\mathrm{L}}$ : the error vector of the linear regression models

The other model is the spatial error model, where the spatial effects are taken into consideration as an error. In this case the model's mathematical representation is the next (3-4) [16].

$$
\begin{gathered}
\mathbf{y}_{(N \times 1)}=\mathbf{X}_{(N \times K)} \boldsymbol{\beta}_{(K \times 1)}+\boldsymbol{\varepsilon}_{(N \times 1)} \\
\boldsymbol{\varepsilon}_{(\mathrm{N} \times 1)}=\lambda \mathbf{W}_{(N \times N)} \boldsymbol{\varepsilon}_{(N \times 1)}+\zeta_{(N \times 1)}
\end{gathered}
$$

where:

- $\zeta$ : vector of spatial dependent errors

$-\lambda$ : autoregressive error parameter

In order to decide which model should be used, the $\mathrm{R}$ project's LMtest order was chosen, which is in the spdep library. This function determines the Lagrange Multiplier test, and its robustness for both model, for a given weight matrix, and a basic linear regression model $[11-14,17]$. 


\section{Results}

\subsection{Choosing the proper model}

Before introducing the results, an important question is need to be answered. In order to analyse the data six weight matrix are constructed. The type of the matrix can be binary (B) or row standardised (W) [13]. The assignment has also four types:

- All: all of the border crossings have effect on each other

- Neighbour: only the neighbouring border crossings have effect on each other

- Main road: only the border crossings have effect on each other which are between two border crossings with $2^{\text {nd }}$ class, or higher road type.

- Country: only the border crossings have effect on each other, where the crossings points toward the same country.

The $a$ parameter for the weight matrices is 1.94 based upon [18].

To choose the proper model, the next table is need to be taken into consideration [17]. Between the parameters, the first is the Moran I's value, and the second is its p-value. The remaining for rows shows the p-values of the Lagrange multiplier (LMerr, LMlag), and the Robust Lagrange multiplier tests (RLMerr, RLMlag), for the two models (where the err stands for the spatial error model, and the lag stands for the spatial lag model) $[8-11,14]$.

Table 2. Choosing the proper model. Source: authors, based on [11-14]

\begin{tabular}{|l|c|c|c|c|c|c|}
\hline & 0. model & 1. model & 2. model & 3. model & 4. model & 5. model \\
\hline Type of matrix & $\mathrm{W}$ & $\mathrm{W}$ & $\mathrm{W}$ & $\mathrm{B}$ & $\mathrm{W}$ & $\mathrm{B}$ \\
\hline Assignment & $\mathrm{All}$ & Neighbour & Main road & Country & Country & Main road \\
\hline Moran I & -0.1392 & -0.1841 & -0.1768 & -0.0386 & -0.1474 & -0.0185 \\
\hline Moran I's p-value & 0.3296 & 0.4276 & 0.3205 & 0.4534 & 0.3811 & 0.2924 \\
\hline LMerr p-value & 0.0796 & 0.0981 & 0.0668 & 0.1494 & 0.0816 & 0.7544 \\
\hline LMlag p-value & 0.6192 & 0.9014 & 0.7861 & 0.7901 & 0.6303 & 0.0594 \\
\hline RLMerr p-value & 0.0175 & 0.0364 & 0.0188 & 0.0153 & 0.0172 & 0.0086 \\
\hline RLMlag p-value & 0.0933 & 0.1982 & 0.1350 & 0.0492 & 0.0899 & 0.0013 \\
\hline
\end{tabular}

\subsection{Comparing the models}

Based on Table 2. five models seem to be appropriate. Among this five models one is spatial lag model, for the $5^{\text {th }}$ matrix (sar5), while the other for are spatial error models for matrices no. 0, 1, 2 and 4 (errorsalm0-errorsalm4). For the five model, the results are shown in Table 4. As it can be seen the error models have better p-values, but the goodness of the models can be seen in other table (Table 3.).

Table 3. Comparing the goodness of the five model. Source: authors, based on [11-14]

\begin{tabular}{|r|c|c|c|c|c|}
\hline & sar5 & errorsalm0 & errorsalm1 & errorsalm2 & errorsalm4 \\
\hline $\mathrm{R}^{2}$ & 0.7839 & 0.8286 & 0.7995 & 0.8118 & 0.8291 \\
\hline$\rho / \lambda$ & 0.0343 & -0.6004 & -0.2909 & -0.4244 & -0.5836 \\
\hline $\mathrm{p}$-value & 0.0820 & $1.04 \mathrm{E}-04$ & $1.24 \mathrm{E}-02$ & $1.95 \mathrm{E}-03$ & $1.30 \mathrm{E}-04$ \\
\hline $\mathrm{L}_{c}$ & -931.1929 & -925.1766 & -929.5786 & -927.9058 & -925.3812 \\
\hline $\mathrm{AIC}$ & 1924.4 & 1912.4 & 1921.2 & 1917.8 & 1912.8 \\
\hline
\end{tabular}


Table 4. Results of the five model. Source: authors, based on [11-14]

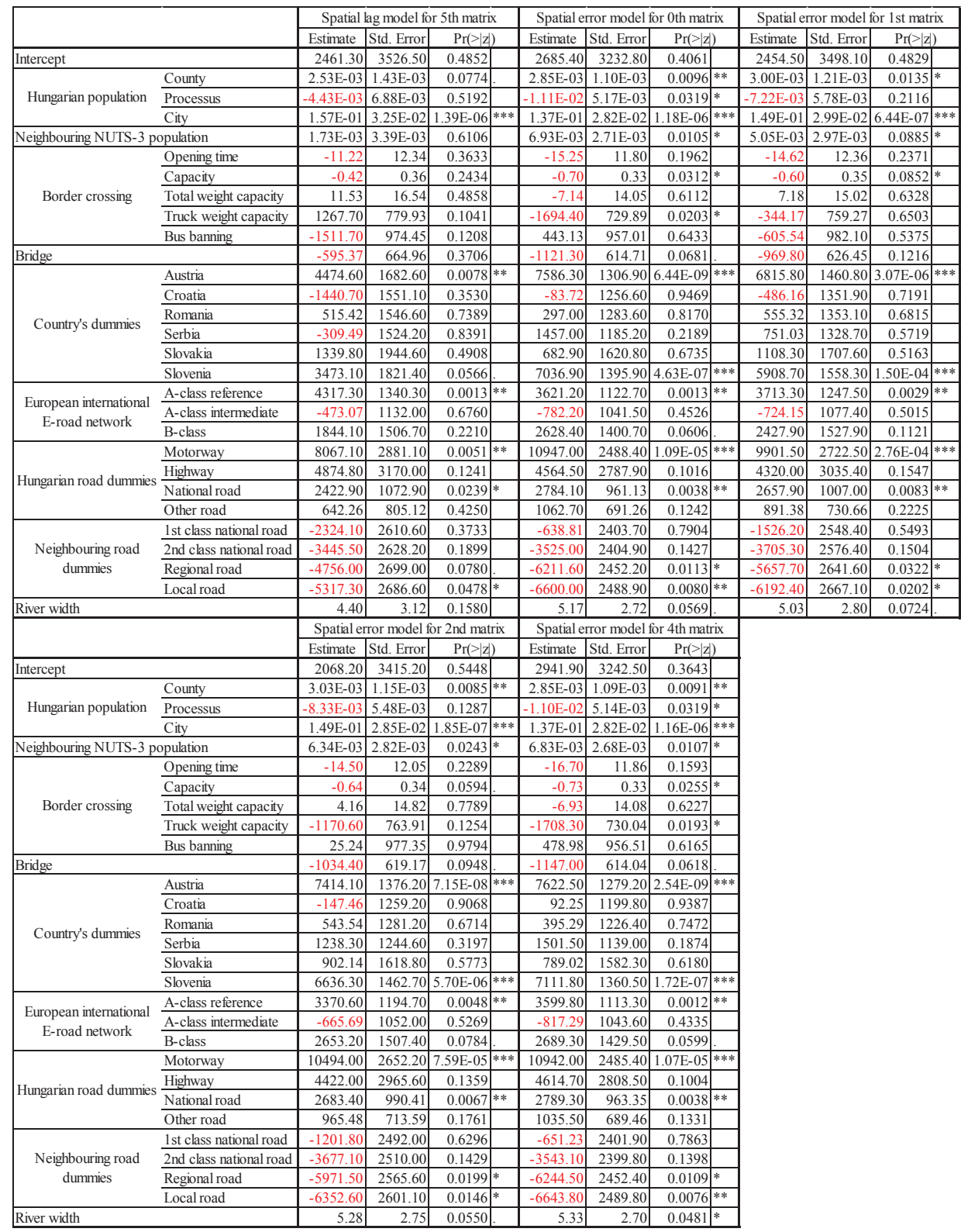

As it can be seen the error models seem to better then the only one lag model. In the first row, the $R^{2}$ values can be seen. In the second row there are the proper autoregressive parameters, and in the third row their p-value. In the fourth and fifth row another qualifying parameters can be seen, the value of the log likelihood, and the AIC (Akaike Information Criteria) which can be calculated from the $L_{c}$ value. There are more accurate information criterias, but because of the constant number of the independent variables, there is no need to use them. Among the error models the all assigned and the country assigned models seem to be the best. 
In the Table 4, every negative estimates are signed by red. As the results are analysed some important facts can be seen. The bridge and the rivers effect have an opposite direction as it expected. This can be because the border can be presented as a legal separator.

At the road effects the Hungarian, and the neighbouring countries road systems provide the expected effects, but the international E-road system's numbers do not provide them, at the A-class intermediate roads. This can be because there are seven border crossings with this kind of E-road classification, and two of them are also A-class reference type too.

Analysed the effects of the neighbouring countries it can be seen, that the strongest relations are with the members of the European Union. The strongest relations are settled with Austria and Slovenia. After them comes Slovakia and Romania. Serbia's and Croatia's effects are not robust; they are changing from model to model. But usually their p-value is also too high.

Analysed the predicted and the real traffics the next statements can be settled. For one hand there are not general rules, that we can set up, like if the model predicts lesser flow then the real, then the border crossing is all right do not need to do anything. In general, two results can indicate the necessity of an upgrade. From one hand if the predicted values are higher, than the counted that can mean that its role can be more serious, but it needs an upgrade. But on the other hand if the predicted is more lesser than the real that indicates that for some reason it is overused, which can be solved by upgrade. So in every case it is need to choose which state is appropriate.

From the data, that can be seen, that in harmony with the long term infrastructure upgrade plans, the upgrades seem to necessary. This means the motorway upgrades (M15, M70), $[19,20]$ and the highway buildings $(42,44,56,8,84,41)$, but it can be seen, that new bridges should be necessary over the Danube $(14,13,11326$ and the ferry).

\section{Conclusion}

After the set up of the spatial econometric model the following properties can be stated. If the spatial lag model is taken into consideration, there is only one model which can be set up. This model has low autoregressive parameter value, with low p-value. The spatial error models bring better results.

To continue the research some additional fact is need to be taken into consideration. For example, in the future it is necessary to destruct the flow data for the different vehicle types. Another interesting direction is to understand better the European International Eroad system. Beside this the international traffic is need to be taken into consideration in the future papers.

This paper is supported by the research project "From horse-drawn railway to intermodal transport" within Visegrad Fund.

\section{References}

1. M. Moniruzzaman, H. Maoh, W. Anderson, Transportation Research Part C: Emerging Technologies 63, 182-194 (2016), DOI: 10.1016/j.trc.2015.12.004

2. H.F. Maoh, S.A. Khan, W.P. Anderson, Journal of Transport Geography 53, 12-21 (2016), DOI: 10.1016/j.jtrangeo.2016.04.002

3. A. Jarašūniene, Transport 20, 4, 165-171 (2005)

4. S. Opasanon, S. Kitthamkesorn, Transport Policy 48, 1-12 (2016) 
5. Japan International Cooperation Agency, Oriental Consultants Global Co., LTD., and Padeco Co., LTD. Preparatory Survey on the Cross-Border Road Network Improvement Project - Final Report 1: Main Repor (Dhaka, Bangladesh, Roads and Highways Department, Ministry of Road Transport and Bridges, The People's Republic of Bangladesh, 2016)

6. United Nations Economic and Social Commission for Asia and the Pacific. The Road Networks connecting China, Kazakhstan, Mongolia, the Russian Federation, and the Korean Peninsula (UNESCAP, 2001)

7. F. Gumz, Á. Török, Periodica Polytechnica Transportation Engineering 43, 2, 92-97 (2015)

8. T. Sipos, Periodica Polytechnica Transportation Engineering 45, 2, 101-105 (2017)

9. I. Trupac, Promet Traffic-Traffico 15, 2, 105-115 (2003)

10. I. Illés, Regionális gazdaságtan - Területfejlesztés, 190-205 (Budapest, TYPOTEX, Hungary, 2008), (in Hungarian)

11. R. Bivand, G. Piras, Journal of Statistical Software 63, 18, 1-36 (2015)

12. R.S. Bivand, J. Hauke, T. Kossowski, Geographical Analysis 45, 2, 150-179 (2013)

13. Roger Bivand et. al., Spatial Dependence: Weighting Schemes, Statistics and Models (Bergen, Norges Handelshøyskole, Norway, 2017), Available online: https://cran.rproject.org/web/packages/spdep/spdep.pdf

14. $\mathrm{R}$ Core Team, A language and environment for statistical computing (Wien, $\mathrm{R}$ Foundation for Statistical Computing, Austria, 2017), Available online: https://www.rproject.org/

15. L. Anselin, Spatial Econometrics: Methods and Models (Dordrecht, Kluwer Academic Publishers, Netherlands, 1988)

16. A. Varga, Térökonometria, Statisztikai szemle 80, 4, 354-370 (2002), (in Hungarian)

17. Ignacio Sarmiento-Barbieri, An Introduction to Spatial Econometrics in R. Champaign, (IL, University of Illinois, USA, 2016), Available online: http://www.econ.uiuc.edu/ lab/workshop/Spatial_in_R.html

18. P. Hagget, Geography. A Global Synthesis (Harlow, The United Kingdom, Pearson Education Limited, 2001)

19. F. Szalóki, $X V$. European Transport Congress and X. Budapest International Road Congress, 12-17 (Budapest, Hungary, 2017)

20. F. Szalóki, XV. European Transport Congress and X. Budapest International Road Congress, 18-24 (Budapest, Hungary, 2017) 